\title{
Caracterização e descrição da estrutura anatômica do lenho de seis espécies arbóreas com potencial medicinal
}

\author{
CURY, G. ${ }^{1 *}$; TOMAZELLO-FILHO, M. $^{2}$ \\ ${ }^{1}$ Universidade de São Paulo - USP/Instituto de Biociências, Departamento de Botânica, Rua do Matão, 277, CEP: \\ 05508-090, São Paulo-Brasil *grazielacury@hotmail.com ${ }^{2}$ Universidade de São Paulo - USP/ Escola Superior de \\ Agricultura "Luiz de Queiroz"-ESALQ, Departamento de Ciências Florestais, Avenida Pádua Dias, 11, Caixa Postal \\ 09, CEP: 13418-900, Piracicaba-Brasil mtomazel@esalq.usp.br
}

\begin{abstract}
RESUMO: A caracterização morfoanatômica e a correta identificação das plantas medicinais são fundamentais para o controle de qualidade dos fitoterápicos. No presente trabalho é caracterizada a anatomia do lenho visando à identificação de seis espécies arbóreas com potencial medicinal. As amostras do lenho foram extraídas por método não destrutivo do tronco das árvores das espécies desenvolvidas em áreas de preservação. Em laboratório as amostras do lenho foram processadas para análises microscópicas do lenho, aplicando as metodologias para estudos de anatomia. Os resultados mostraram que o parênquima axial foi o parâmetro anatômico mais efetivo para a distinção das espécies através da análise do seu lenho. No trabalho discute-se a importância da aplicação da anatomia do lenho como ferramenta na identificação de espécies arbóreas medicinais.
\end{abstract}

Palavras-chave: plantas medicinais, anatomia do lenho, identificação de espécies

\begin{abstract}
Characterization and description of wood anatomical structure in six tree species with medicinal potential. The morphoanatomical characterization and the correct identification of medicinal plants are fundamental for the quality control of phytotherapics. In the present work, wood anatomy was characterized in order to identify six tree species with medicinal potential. Wood samples were collected through a non-destructive method from the trunk of trees developed in conservation areas. In the laboratory, wood samples were processed for microscopic analysis by applying the methods for anatomical studies. Axial parenchyma was the most effective anatomical parameter to distinguish species through wood analysis. In this work, the importance of wood anatomy as a tool for the identification of medicinal tree species was discussed.
\end{abstract}

Key words: medicinal plants, wood anatomy, species identification

\section{INTRODUÇÃO}

As florestas neotropicais são reconhecidamente caracterizadas pela significativa diversidade de espécies vegetais e, dentre estas, incluem-se as com potencial medicinal (Wilson \& Peter, 1995; Gurib-Fakim, 2006). No entanto, a correta identificação botânica das espécies medicinais é fundamental para o desenvolvimento das pesquisas em farmacologia, bem como para assegurar a conservação genética e manutenção da biodiversidade. Nesse aspecto, as limitações na identificação das espécies arbóreas relacionam-se à época e acesso para a coleta das estruturas botânicas reprodutivas na copa das árvores, florescimento irregular e ocorrendo somente em exemplares adultos, morfologia distinta em cada fase do desenvolvimento, dentre outras (Santos et al., 1998). O lenho constitui um seguro parâmetro aplicado na identificação das espécies arbóreas, através da descrição e análise das suas características anatômicas macro e microscópicas (IPT, 1985).

Atualmente verifica-se crescente aumento nas pesquisas com plantas medicinais nos laboratórios de instituições de pesquisa e de empresas privadas, com o objetivo de isolar substâncias químicas com atividade farmacológica sendo que, apenas no Brasil, o mercado de fitoterápicos movimenta cerca de US\$ 160 milhões/ano (Ríos \& Recio, 2005). Em nosso país o registro de medicamentos fitoterápicos é

Recebido para publicação em 07/12/2009

Aceito para publicação em 22/11/2010

Rev. Bras. PI. Med., Botucatu, v.13, n.3, p.311-318, 2011. 
regulamentado pela Resolução de Diretoria Colegiada/ RDC 48/2004, a qual determina o padrão de qualidade, comprovação da eficácia e segurança para a indicação terapêutica proposta, além da necessidade da identificação botânica (Carvalho et al., 2008). A identificação e caracterização morfo-anatômica das plantas são fundamentais no controle da qualidade da matéria-prima para a elaboração de fitoterápicos, como garantia da confiabilidade (Ming, 1994).

$\mathrm{Na}$ literatura científica há relatos de significativo número de espécies arbóreas como fonte de produtos não madeireiros, com destaque para o princípio ativo de fármacos o que não tem recebido a devida atenção, nos conceitos de uso múltiplo e sustentado dos recursos florestais.

Dentre as plantas arbóreas com potencial medicinal podem ser destacadas espécies da família Lecythidaceae como Cariniana legalis (Mart.) O. Ktze, cuja casca possui ação antimicrobiana (Almeida et al., 1998) e Cariniana estrellensis (Raddi) O. Ktze., cuja casca possui ação antifúngica (Janovik et al., 2009) e da família Fabaceae, como Anadenanthera macrocarpa Benth., cujas folhas possuem ação depurativa (Burle, 1988), Platycyamus regnelliBenth., na qual casca e raízes têm com ação antitérmica (Almeida et al.,1998), Caesalpinia ferrea Mart., cujo fruto possui ação antimicrobiana (Storey \& Salem, 1997) e Cassia ferruginea Schrad., na qual as sementes têm ação laxativa (Mors et al., 2000).

Desta forma, este trabalho teve como objetivo descrever a anatomia microscópica do lenho das seis espécies citadas acima ocorrentes no Estado de São Paulo com potencial medicinal, como subsídio para identificação e conservação da biodiversidade.

\section{MATERIAL E MÉTODO}

Áreas de coleta

As amostras de lenho das árvores das seis espécies florestais foram coletadas em cinco localidades, a saber (i) Estação Ecológica de lbicatu (EEI), do Instituto Florestal, no município de Piracicaba; (ii) Reserva Estadual de Porto Ferreira (REPF), do Instituto Florestal no município de Porto Ferreira; (iii) Arboreto Experimental da Duratex S.A. (AED), no município de Agudos; (iv) Estação Experimental de Santa Rita do Passa Quatro (EESRPQ), do Instituto Florestal no município de Santa Rita do Passa Quatro; (v) Estação Experimental de Tupi (EET), do Instituto Florestal, no município de Piracicaba.

\section{Coleta das amostras do lenho}

Nas florestas naturais e plantações relacionadas foram selecionadas árvores de seis espécies com potencial medicinal (Tabela 1). De três árvores adultas de cada espécie foram extraídas amostras do lenho na altura do DAP $(1,30 \mathrm{~m})$ do tronco, por método não destrutivo, com extrator motorizado acoplado a uma sonda metálica (Cury et al., 2001).

\section{Análise das amostras do lenho}

Para a análise anatômica, corpos-de-prova do lenho $\left(1 \mathrm{~cm}^{3}\right)$ foram obtidos a partir das amostras coletadas e fervidos em solução de água e glicerina (4:1) (Ferreirinha, 1958) para o amolecimento. Secções nos planos transversal, longitudinal tangencial e longitudinal radial (15-20 $\mu \mathrm{m}$ espessura) foram obtidas em micrótomo de deslize. As secções foram clarificadas com hipoclorito de sódio (50\%), coradas com safranina ( $1 \%$ e e montadas em bálsamo do Canadá para obtenção de lâminas permanentes (Johansen, 1940) analisadas sob microscópio de luz.

Os dados quantitativos medidos foram frequência, diâmetro e comprimento de elementos de vasos, diâmetro de pontoações intervasculares, comprimento e espessura da parede das fibras e altura dos raios. Para a mensuração da espessura da parede

TABELA 1. Comparação das médias após análise estatística $(F=$ frequência; $D T=$ diâmetro tangencial; $C=$ comprimento; PIV = pontoação intervascular; $A$ = altura).

\begin{tabular}{|c|c|c|c|c|c|c|}
\hline \multirow[t]{2}{*}{ Espécie } & \multicolumn{3}{|c|}{ Vasos } & \multirow{2}{*}{$\begin{array}{c}\text { PIV } \\
\text { DT } \\
(\mu \mathrm{m})\end{array}$} & \multirow{2}{*}{$\begin{array}{l}\text { Fibras } \\
\text { C } \\
(\mathrm{mm})\end{array}$} & \multirow{2}{*}{$\begin{array}{c}\text { Raios } \\
\text { A } \\
(\mathrm{mm})\end{array}$} \\
\hline & $\begin{array}{c}\mathrm{F} \\
\left(\mathrm{mm}^{2}\right)\end{array}$ & $\begin{array}{c}\text { DT } \\
(\mu \mathrm{m})\end{array}$ & $\begin{array}{c}\mathrm{C} \\
(\mathrm{mm})\end{array}$ & & & \\
\hline Cariniana legalis & $20(a)$ & $108,1(\mathrm{a})$ & $0,50(a)$ & $9,60(a)$ & $1,40(a)$ & $0,50(a)$ \\
\hline Cariniana estrellensis & $5(b)$ & $125,5(a)$ & $0,40(a)$ & $10,0(a)$ & $1,53(a)$ & $0,33(b)$ \\
\hline Anadenanthera macrocarpa & $20(a)$ & $157,0(b)$ & $0,25(b)$ & $8,50(b)$ & $1,00(b)$ & $0,27(b)$ \\
\hline Platycyamus regnelli & 5 (b) & $142,2(b)$ & $0,40(a)$ & $13,0(c)$ & $0,40(\mathrm{c})$ & $0,39(a)$ \\
\hline Caesalpinia ferrea & $5(b)$ & 92,6 (c) & $0,30(b)$ & $8,30(b)$ & $1,10(b)$ & $0,18(c)$ \\
\hline Cassia ferruginea & $5(b)$ & $131,3(a)$ & $0,25(b)$ & $6,10(d)$ & $1,00(b)$ & $0,18(c)$ \\
\hline
\end{tabular}

Médias seguidas pela mesma letra na linha, não diferem entre si pelo teste de Tukey a $5 \%$ de probabilidade 
das fibras, do comprimento dos vasos e para a análise de apêndices nos elementos de vaso, foi realizada a dissociação dos elementos celulares por maceração de segmentos do lenho segundo Franklin (1937). O número de medições foi fixado $\mathrm{em} n=10$ para diâmetro tangencial de pontoação e para os demais parâmetros foi fixado um $n=30$. Para as quantificações do diâmetro das paredes das fibras e das pontoações intervasculares utilizou-se um microscópio de luz com tambor micrométrico, e para o diâmetro, comprimento e frequência de vasos e altura dos raios foi utilizado microscópio de projeção em mesa em sala escura. Os valores obtidos foram convertidos em micrômetros através de fator de conversão. Para comparação entre as médias das seis espécies foi realizada análise estatística utilizando o estudo com dados inteiramente casualizados, seguido do teste de Tukey, ao nível de $5 \%$ de probabilidade para todas as variáveis quantificadas. Toda a análise foi realizada com base nas normas de IAWA Committee (1989). As imagens foram capturadas digitalmente através de microscópio Leica DM LB com uma câmera de vídeo acoplada a um computador, no qual foi utilizado o software IM50 para análise de imagens.

\section{RESULTADO}

Em Cariniana legalis, ocorrem vasos com porosidade difusa, frequência $20 \mathrm{~mm}^{-2}$, solitários e múltiplos, forma da secção arredondada (Figura 1), placas de perfuração simples, com diâmetro tangencial de $108,1 \mu \mathrm{m}$, elementos vasculares com $0,5 \mathrm{~mm}$ de comprimento, com 1 ou ausência de apêndices, tilos abundantes, pontoações intervasculares alternas (Figura 3), arredondadas, com diâmetro tangencial de $9,6 \mu \mathrm{m}$ e pontoações radiovasculares semelhantes às intervasculares. $O$ parênquima axial está disposto em linhas finas e aproximadas, formando um reticulado com os raios (Figura 1). Fibras com 1,4 mm de comprimento e paredes delgadas a espessas. Raios uni e bisseriados, com 0,509 $\mathrm{mm}$ de altura (Figura 2), homocelulares com todas as células procumbentes (Figura 4). Cristais presentes em células de parênquima axial. Sílica em células do parênquima radial. Camadas de crescimento individualizadas por zonas fibrosas tangenciais mais escuras.

Em Cariniana estrellensis ocorrem vasos com porosidade difusa, frequência de $5 \mathrm{~mm}^{-2}$, solitários e múltiplos em cadeias radiais, forma da secção arredondada (Figura 5), placas de perfuração simples, com diâmetro tangencial de 125,5 $\mu \mathrm{m}$, elementos vasculares com $0,4 \mathrm{~mm}$ de comprimento, com presença de 1, 2 (Figura 10) ou ausência de apêndices, tilos não abundantes, pontoações intervasculares alternas, arredondadas, com diâmetro tangencial de 10,0 $\mu \mathrm{m}$, e pontoações radiovasculares
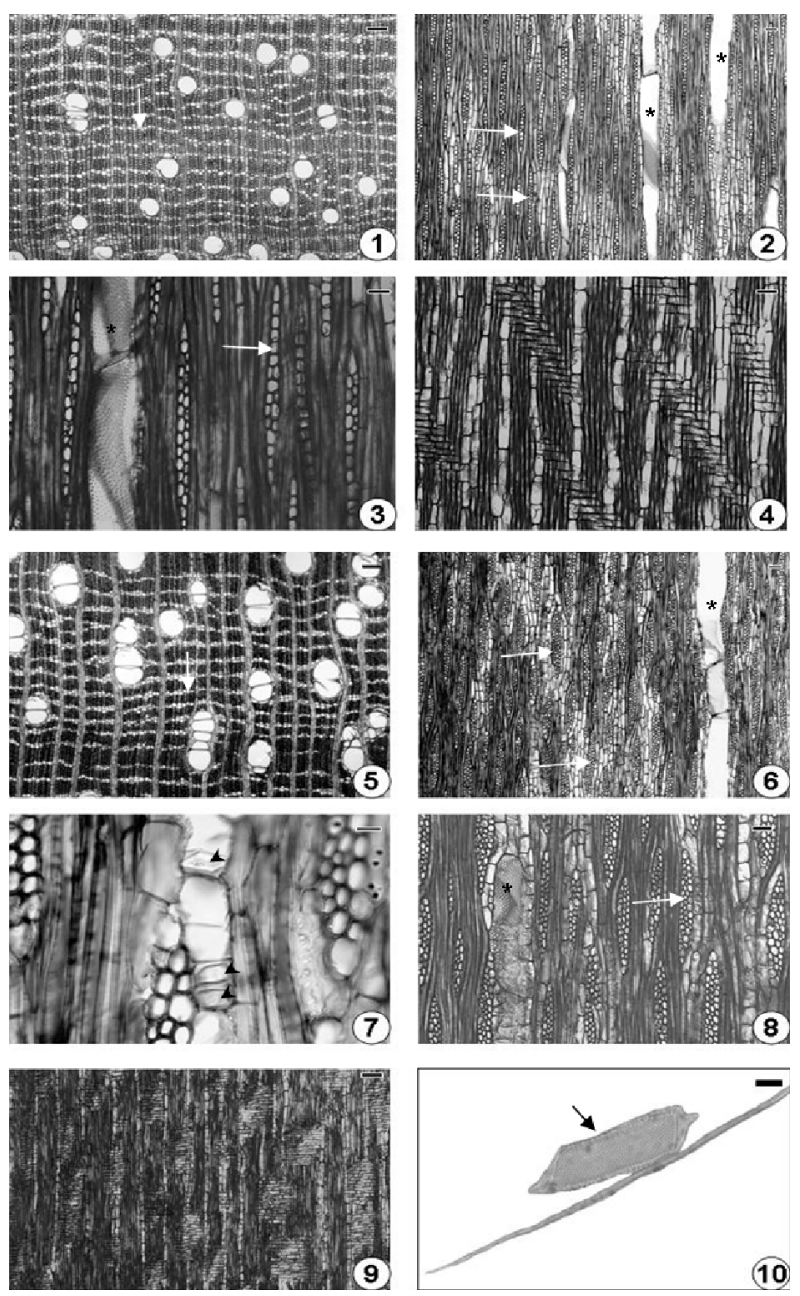

FIGURAS 1 - 4. Cariniana legalis. 5 - 10. Cariniana estrellensis. 1, 5. Secções transversais evidenciando o parênquima axial (setas). 2, 3, 6, 7, 8. Secções longitudinais tangenciais evidenciando os raios (setas) e os elementos de vaso $\left({ }^{*}\right)$. Notar na figura 7 os cristais em células do parênquima axial (ponta de seta). 4, 9. Secções longitudinais radiais mostrando os raios homocelulares. 10. Material macerado com um elemento de vaso (seta) e uma fibra. Barras: $(1,2,5,6$, 9) $=200 \mu \mathrm{m} ;(3)=50 \mu \mathrm{m} ;(4,8,10)=10 \mu \mathrm{m} ;(7)=30$ $\mu \mathrm{m}$.

semelhantes às intervasculares. Parênquima axial disposto em linhas finas, formando um reticulado com os raios (Figura 5). Fibras com 1,53 $\mathrm{mm}$ de comprimento e paredes muito espessas. Raios trisseriados e alguns unisseriados (Figuras 6 - 8), com $0,334 \mathrm{~mm}$ de altura, homocelulares com todas as células procumbentes (Figura 9). Cristais presentes em células de parênquima axial (Figura 7). Sílica presente em células de parênquima axial e radial. Camadas de crescimento individualizadas pela variação do lume das fibras.

Em Anadenanthera macrocarpa ocorrem vasos com porosidade difusa, frequência de $20 \mathrm{~mm}^{-2}$, 

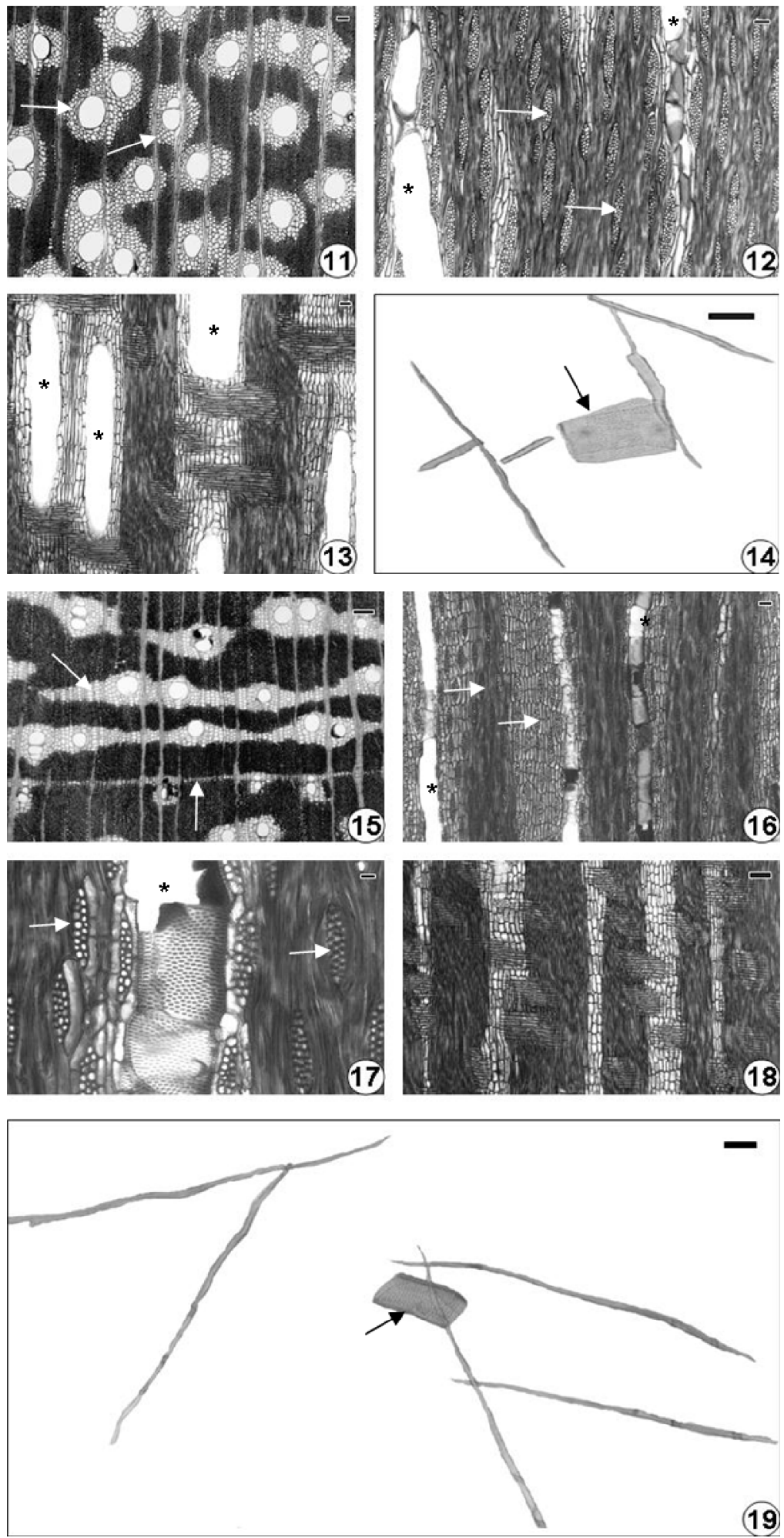

FIGURAS 11 - 14. Anadenanthera macrocarpa. 15 - 19. Caesalpinia ferrea. 11, 15. Secções transversais evidenciando o parênquima axial (setas). 12, 16, 17. Secções longitudinais tangenciais evidenciando os raios (setas) e os elementos de vaso $\left(^{*}\right)$. 13, 18. Secções longitudinais radiais mostrando os raios homocelulares e elementos de vaso $\left(^{*}\right) .14,19$. Material macerado mostrando elementos de vaso (seta) e fibras. Barras: $(11,12,13,15,18)=200$ $\mu \mathrm{m} ;(14,16,19)=(17)=50 \mu \mathrm{m}$. 
solitários e múltiplos, forma da secção arredondada (Figura 11), placa de perfuração simples, com diâmetro tangencial de 157,0 $\mu \mathrm{m}$, elementos vasculares com $0,25 \mathrm{~mm}$ de comprimento, com 1 ou ausência de apêndices (Figura 14), tilos não abundantes, depósitos nos vasos marrom claro não abundantes, pontoações intervasculares alternas, arredondadas, com diâmetro tangencial de $8,5 \mu \mathrm{m}$, pontoações radiovasculares semelhantes às intervasculares. Parênquima axial paratraqueal vasicêntrico, também aliforme com pequenas confluências e em linhas marginais (Figura 11). Fibras com $1,0 \mathrm{~mm}$ de comprimento e paredes muito espessas. Raios tri e multisseriados (Figura 12), com $0,274 \mathrm{~mm}$ de altura, homocelulares com todas as células procumbentes (Figura 13). Cristais presentes em células do parênquima axial. Camadas de crescimento individualizadas pelo achatamento do lume das fibras.

Em Caesalpinia ferrea ocorrem vasos com porosidade difusa, frequência de $5 \mathrm{~mm}^{-2}$, arranjo diagonal oblíquo, solitários na maioria, forma da secção arredondada (Figura 15), placas de perfuração simples, diâmetro tangencial de $92,6 \mu \mathrm{m}$, elementos vasculares com $0,3 \mathrm{~mm}$ de comprimento, com ausência de apêndices (Figura 19), tilos abundantes, depósitos nos vasos abundantes com cor marrom escura, pontoações intervasculares alternas arredondadas, com diâmetro tangencial de 8,3 $\mu \mathrm{m}$, pontoações radiovasculares semelhantes às intravasculares. Parênquima axial aliforme losangular confluente formando faixas e em linhas de parênquima marginal (Figura 15). Fibras com 1,1 mm de comprimento e paredes muito espessas. Raios bi e trisseriados (Figuras $16 \mathrm{e} \mathrm{17),} \mathrm{com} \mathrm{altura} \mathrm{de} 0,184 \mathrm{~mm}$, homocelulares com todas as células procumbentes (Figura 18), estratificados (Figura 16). Cristais em células do parênquima axial. Sílica presente no parênquima radial. Camadas de crescimento individualizadas pela variação do lume das fibras.

Em Cassia ferruginea ocorrem vasos com porosidade difusa, frequência de $5 \mathrm{~mm}^{-2}$, solitários na maioria e alguns múltiplos de 2 a 3 , forma da secção arredondada (Figura 20), placas de perfuração simples, com diâmetro tangencial de 131,3 $\mu \mathrm{m}$, elementos vasculares com $0,25 \mathrm{~mm}$ de comprimento, com 1 ou ausência de apêndices (Figura 23), tilos abundantes, depósitos nos vasos abundantes de cor marrom, pontoações intervasculares alternas, arredondadas, guarnecidas, com 6,1 $\mu \mathrm{m}$ de diâmetro tangencial, pontoações radiovasculares semelhantes às intervasculares. Parênquima axial paratraqueal aliforme losangular e linhas de parênquima marginal (Figura 20). Fibras com $1 \mathrm{~mm}$ de comprimento e paredes delgadas a espessas. Raios uni e bisseriados (Figura 21), com altura de 0,183 mm, homocelulares com todas as células procumbentes (Figura 22).
Camadas de crescimento também individualizadas pelo achatamento do lume das fibras.

Em Platycyamus regnelliocorrem vasos com porosidade difusa, frequência de $5 \mathrm{~mm}^{-2}$, solitários e alguns múltiplos de 2 a 4 , forma da secção ovalada (Figura 24 e 25), placas de perfuração simples, com diâmetro tangencial de $142,2 \mu \mathrm{m}$, elementos vasculares com $0,4 \mathrm{~mm}$ de comprimento, com ausência de apêndices (Figura 29), tilos não abundantes, depósitos nos vasos pouco abundantes de cor amarelada, pontoações intervasculares alternas, arredondadas, guarnecidas (Figura 27), com diâmetro tangencial de 13,0 $\mu \mathrm{m}$, pontoações radiovasculares semelhantes às intervasculares. Parênquima axial aliforme confluente, formando faixas irregulares e em linhas marginais (Figuras 24 e 25). Fibras com 0,4 mm de comprimento e paredes muito espessas. Raios multisseriados na maioria (Figura 26) e alguns unisseriados, com altura de $0,399 \mathrm{~mm}$, heterocelulares com células procumbentes e 1 fileira marginal de células quadradas e eretas, com estratificação irregular (Figura 28). Cristais presentes em células do parênquima axial. Camadas de crescimento distintas individualizadas por linhas de parênquima marginal.

\section{DISCUSSÃO}

As espécies Cariniana legalis e $C$. estrellensis, ambas pertencentes à família Lecythidaceae, apresentam características anatômicas muito semelhantes, de forma que a distinção entre as duas espécies é dificultada até mesmo em análises microscópicas. O parênquima axial, reconhecido como um dos mais importantes parâmetros de identificação de espécies pela anatomia do lenho (Wheeler et al., 1986; Chimelo et al., 1993), apresenta a mesma disposição nas duas espécies. Desta forma, as características anatômicas que melhor permitem a distinção são os apêndices dos elementos de vaso (1 ou nenhum em $C$. legalis e 1, 2 ou nenhum em $C$. estrellensis), a frequência dos vasos (20 $\mathrm{mm}^{-2} \mathrm{em} \mathrm{C}$. legalis e $5 \mathrm{~mm}^{-2} \mathrm{em} \mathrm{C}$. estrellensis), a largura dos raios em número de células (uni e bisseriados em $C$. legalis e trisseriados, na maioria, em C. estrellensis) e a altura dos raios $0,50 \mathrm{~mm}$ em $C$. legalis e 0,33 em $C$. estrellensis).

Dentre as espécies pertencentes à família Fabaceae, Platycyamus regnellié a que apresenta maior quantidade de características peculiares em relação às demais, como a forma da secção ovalada, raios heterocelulares e pontoações intervasculares com maior diâmetro tangencial e guarnecidas. Pontoações guarnecidas ocorrem em cerca de 50 famílias de Angiospermas, entre as quais, Leguminosae, Vochysiaceae e Myrtaceae (Metcalfe \& Chalk, 1950; Détienne \& Jacquet, 1983; Carlquist, 2001) e o valor

Rev. Bras. Pl. Med., Botucatu, v.13, n.3, p.311-318, 2011. 

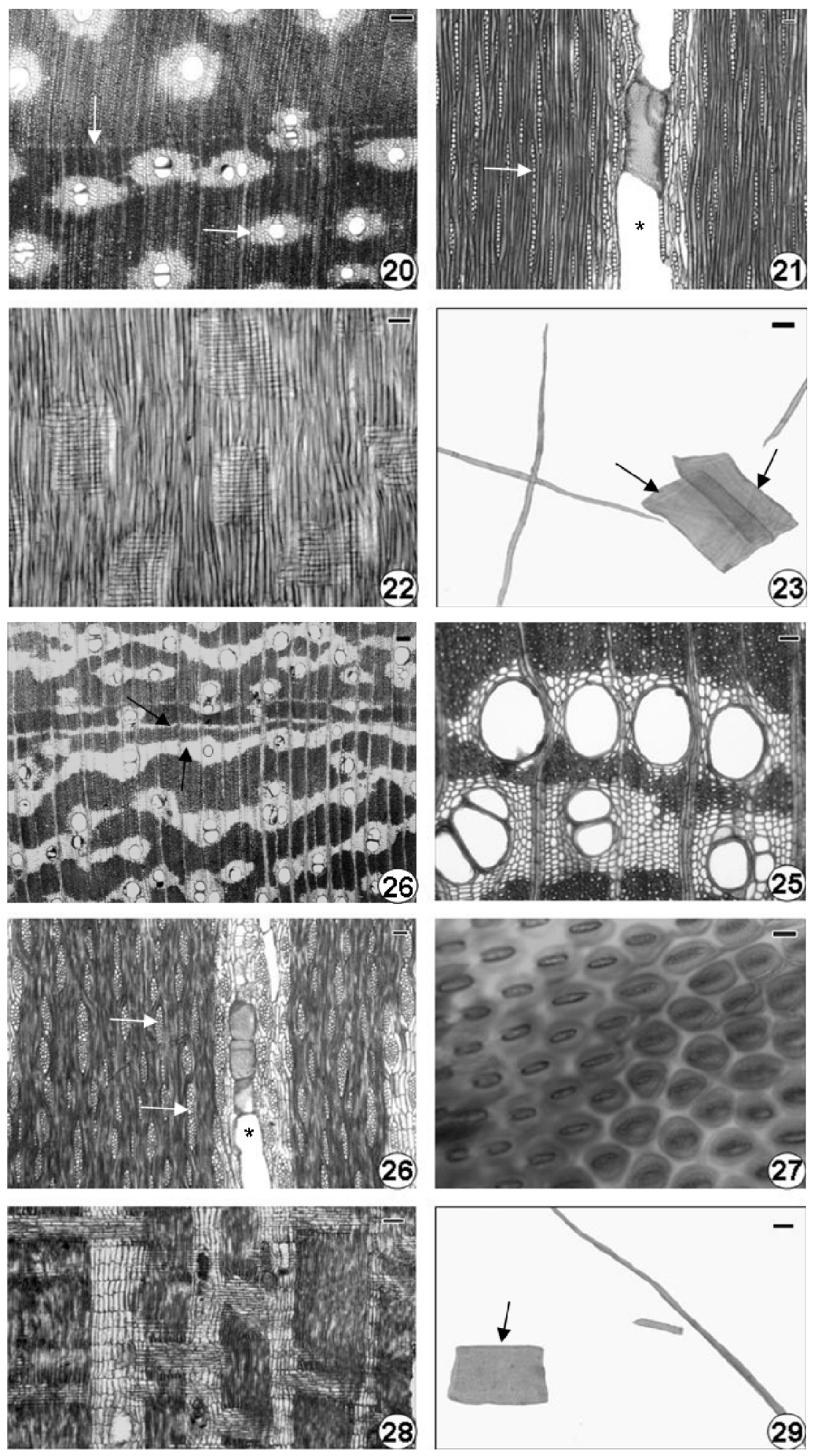

FIGURAS 20 - 23. Cassia ferruginea. 24 - 29. Platycyamus regnelli. 20, 24, 25. Secções transversais evidenciando o parênquima axial (setas). Notar na Figura 25 os vasos com secção ovalada. 21, 26, 27. Secções longitudinais tangenciais evidenciando os raios (setas), os elementos de vaso ( $\left.{ }^{*}\right)$ e as pontoações intervasculares guarnecidas (ponta de seta). 22, 28. Secções longitudinais radiais mostrando os raios homocelulares em 22 e heterocelulares em 28. 23, 29. Material macerado mostrando elementos de vaso (seta) e fibras. Barras: $(20,26,28)=200 \mu \mathrm{m} ;(21$, $22,23,24,25,29) ;(27)=10 \mu \mathrm{m}$. 
taxonômico é citado por diversos autores (Metcalfe \& Chalk, 1950; Baas, 1982; Van Vliet \& Baas, 1984). A presença pode ser reconhecida como um caráter diagnóstico importante sob o ponto de vista taxonômico, pois estão restritas a certas famílias e algumas ordens (Bailey, 1933).

As outras espécies da família Fabaceae, apesar de não apresentarem tantas semelhanças anatômicas, apresentam a disposição do parênquima axial muito parecida entre elas, já que em todas ocorre parênquima axial aliforme losangular. Desta forma é válido destacar características que permitem a separação dessas espécies, como o diâmetro tangencial dos vasos (157,0 $\mu \mathrm{m}$ em $A$. macrocarpa, 92,6 $\mu \mathrm{m}$ em C. ferrea e $131,3 \mu \mathrm{m}$ em $C$ ferruginea) e a largura dos raios em número de células (tri e multisseriados em $A$. macrocarpa, bi e trisseriados em $C$. ferrea e uni e bisseriados em $C$. ferruginea).

As espécies descritas neste estudo, além de apresentarem potencial para a fabricação de fármacos, possuem madeiras comumente utilizadas para outros fins como construção civil, fabricação de móveis, acabamentos internos, marcenaria em geral ou instrumentos musicais (Mainieri \& Chimelo, 1989; Lorenzi, 1992; Angyalossy et al., 2005; Paula \& Alves, 2007). Desta forma, as características anatômicas do lenho dessas espécies já se encontram registradas na literatura. No entanto, ao proceder a comparação entre as descrições deste trabalho e as anteriormente publicadas, nota-se que as características anatômicas microscópicas da madeira dessas espécies pode, algumas vezes, apresentar diferenças.

No entanto, de acordo com Ribeiro \& Barros (2006), a diversidade estrutural encontrada no xilema secundário das plantas lenhosas tem uma explicação adaptativa e funcional e pode estar diretamente associada ao hábito da planta assim como às variações das condições atmosféricas e à disponibilidade hídrica, o que pode explicar as divergências encontradas entre os resultados aqui obtidos e os da literatura. As variações ambientais levam a alterações estruturais no lenho, principalmente quanto às dimensões dos elementos celulares (Barajas-Morales, 1985; Wilkins \& Papassotiriou, 1989; Arnold \& Mauseth, 1999; Noshiro \& Baas, 2000).

As dimensões das células vegetais, dentre elas os elementos de vasos e as fibras, dependem de características genéticas e de fatores ecológicos, que podem interferir nas características ontogenéticas como o comprimento das iniciais fusiformes que originarão tanto os elementos de vaso quanto as fibras. Em condições de maior disponibilidade hídrica do ambiente, as iniciais fusiformes apresentarão maior turgor celular, resultando em elementos axiais de tamanho maior (Luchi, 2004). Em relação ao diâmetro das pontoações intervasculares, Luchi (2004), ao analisar o caule de Croton urucurana, constatou as maiores médias para indivíduos da área alagada.

Já em relação aos raios parenquimáticos, estes podem apresentar-se em diferentes formas, prevalecendo raios multisseriados em ambientes secos (Carlquist, 1966). Chimelo \& Mattos-Filho (1988 ap ud Alves \& Angyalossy-Alfonso, 2002) observaram a ocorrência de raios mais largos no cerrado e na caatinga, enquanto em amostras de floresta os raios eram mais estreitos.

O lenho constituiu-se, desta forma, em importante ferramenta para a identificação das espécies arbóreas, devendo-se observar as suas características sensoriais (cor, densidade, odor, gosto, dureza, etc.) e anatômicas macro e microscópicas (Marchiori, 2004). As condições do ambiente nas quais as plantas lenhosas e medicinais se desenvolvem devem, da mesma forma, ser consideradas pelo efeito na biomassa e teor de princípios ativos (Ming, 1994). No entanto, muitas espécies vegetais vêm sendo exploradas como fonte de fitoterápicos sem atender aos princípios de uso racional e sustentado, com risco de extinção.

De acordo com Ferreira et al. (1998), a indústria farmacêutica nacional de fitoterápicos necessita de maiores investimentos no controle de qualidade para atingir os padrões mundiais estabelecidos nas farmacopéias e códigos oficiais, recomendando-se intensificar pesquisas químicas, farmacológicas e de correta identificação das espécies, além do estabelecimento de plantações. Nesse aspecto, os resultados do presente estudo demonstram que a anatomia do lenho pode ser aplicada na identificação de espécies com potencial medicinal sendo, no entanto, importante para sua aplicação como metodologia laboratorial de rotina, a observância das diferenças anatômicas encontradas entre indivíduos da mesma espécie, porém provenientes de locais com condições ambientais distintas. Desta forma, ressalta-se a necessidade de comparação entre esses indivíduos, o que só é possível graças à literatura existente, a qual muitas vezes apresenta para uma mesma espécie, diferentes descrições devido à procedência da amostra.

\section{AGRADECIMENTO}

Os autores agradecem à Fundação de Amparo à Pesquisa do Estado de São Paulo (FAPESP), pela concessão da Bolsa de Mestrado para a primeira autora; aos Técnicos de Laboratório Antônio Carlos F. Barbosa e Maria Aparecida C. Bermudes, pelo auxílio na montagem das lâminas histológicas e ao Departamento de Botânica (IB-USP), pela utilização dos recursos de microscopia.

\section{REFERÊNCIA}

ALMEIDA, S.P. et al. Cerrado: espécies vegetais úteis. Planaltina: EMBRAPA, 1998. 464p.

ALVES, E.S.; ANGYALOSSY-ALFONSO, V. Ecological

Rev. Bras. Pl. Med., Botucatu, v.13, n.3, p.311-318, 2011. 
trends in the wood anatomy of some brazilian species. 2. axial parenchyma, rays and fibres. IAWA Bulletin, v.23, p.391-418, 2002.

ANGYALOSSY, V.; AMANO, E.; SEGALA-ALVES, E. Madeiras utilizadas na fabricação de arcos para instrumentos de corda: aspectos anatômicos. Acta Botanica Brasilica, v.19, p.819-34, 2005.

ARNOLD, D.H.; MAUSETH, J.D. Effects of environmental factors on development of wood. American Journal of Botany, v.86, p.367-71, 1999.

BAAS, P. Systematic, phylogenetic and ecological wood anatomy: history and perspectives. In: BAAS, P. (Ed). New perspectives in wood anatomy. The Netherlands: The Hangue Martinus Nijhoff Publishers, 1982. p.23-58.

BAILEY, I.W. The cambium and its derivate tissues. VIII: tructure, distribution and diagnostic significance of the vestured pits in dicotyledons. Journal Arnold Arbor, v.14, p.259-73, 1933.

BARAJAS-MORALES, J. Wood structural differences between trees of two tropical forests in Mexico. IAWA Bulletin, v.6, n.4, p.355-64, 1985.

BURLE, M. Árvores: trees Minas Gerais. Rio de Janeiro: AC\&M, 1988. 91p.

CARLQUIST, S. Wood anatomy of Compositae: a summary, with comments on factors controlling wood evolution. Aliso, v.6, p.25-44, 1966.

CARLQUIST, S. Comparative wood anatomy: systematic, ecological and evolutionary aspects of dicotyledons wood. Berlin: Springer Verlag, 2001. 434p.

CARVALHO, A.C.B. et al. Situação do registro de medicamentos fitoterápicos no Brasil. Revista Brasileira de Farmacognosia, v.18, p.314-9, 2008.

CHIMELO, J.P. et al. IMAC: identificação de madeiras brasileiras com auxílio do computador. São Paulo: IPT, 1993. 56p.

CURY, G.; TOMAZELLO-FILHO, M.; LISI, C.S. Aplicação de método não destrutivo na coleta de amostras de madeira de espécies arbóreas nativas para estudo anatômico. In: SIMPÓSIO BRASILEIRO DE PÓS-GRADUAÇÃO EM ENGENHARIA FLORESTAL, 1., 2001, Santa Maria. Santa Maria: Universidade Federal de Santa Maria, 2001. p.80-9. DÉTIENNE, P.; JACQUET, P. Atlas d'indentification des bois de l'Amazonie et régions voisines. Nogent-surMarne: Centre Technique Forestier Tropical, 1983. 640p. FERREIRA, S.H. et al. Medicamentos a partir de plantas medicinais no Brasil. Rio de Janeiro: Academia Brasileira de Ciências, 1998. 133p.

FERREIRINHA, M.P. Glossário internacional dos termos usados em anatomia de madeiras. Lisboa: Ministério do Ultramar - Junta de Investigações do Ultramar, 1958. 89p. FRANKLIN, G.L. Permanent preparations of macerated wood fibers. Tropical Woods, v.49, p.21-2, 1937.

GURIB-FAKIM, A. Medicinal plants: traditions of yesterday and drugs of tomorrow. Molecular Aspects of Medicine, v.27, p.1-93, 2006.

IAWA COMMITTEE. List of microscopic features for hardwood identification. IAWA Bulletin, v.10, p.219-332, 1989.

IPT. Madeiras da Reserva Florestal de Curuá-Una, Estado do Pará: caracterização anatômica, propriedades gerais e aplicações. São Paulo: IPT, 1981. 117p.

JANOVIK, V. et al. Doseamento de polifenóis, flavonóides e taninos no extrato bruto e frações de Cariniana domestica (Mart.) Miers. Saúde, v.35, p.25-8, 2009.

JOHANSEN, D.A. Plant microtechnique. New York: Mc Graw - Hill Book Company, 1940. 523p.

LORENZI, H. Árvores brasileiras: manual de identificação e cultivo de plantas arbóreas nativas do Brasil. Nova Odessa: Plantarum, 1992. 368p.

LUCHI, A.E. Anatomia do lenho de Croton urucurana Baill. (Euphorbiaceae) de solos com diferentes níveis de umidade. Revista Brasileira de Botânica, v.27, p.271-80, 2004.

MAINIERI, C.; CHIMELO, J.P. Fichas de características das madeiras brasileiras. São Paulo: IPT, 1989. 432p. MARCHIORI, J.N.C. Elementos de dendrologia. Santa Maria: Ed. da UFSM, 2004. 176p.

METCALFE, C.R.; CHALK, L. Anatomy of the Dicotyledons: leaves, stem and wood in relation to taxonomy with notes on economic uses. Oxford: Clarendon Press, 1950. 1500p.

MING, L.C. Estudos e pesquisas de plantas medicinais na agronomia. Horticultura Brasileira, v.12, p.3-9, 1994. MORS, W.B.; RIZZINI, C.T.; PEREIRA, N.A. Medicinal plants of Brazil. Michigan: Reference Publication, 2000. 501p. NOSHIRO, S.; BAAS, P. Latitudinal trends in wood anatomy within species and genera: case study in Cornus S.L. (Cornaceae). American Journal of Botany, v.87, p.1495506, 2000.

PAULA, J.E.; ALVES, J.L.H. 897 madeiras nativas do Brasil: anatomia, dendrologia, dedrometria, produção e uso. Porto Alegre: Cinco Continentes, 2007. 435p.

RIBEIRO, M.L.R.C.; BARROS, C.F. Variação intraspecífica do lenho de Pseudopiptadenia contorta (DC.) G.P. Lewis \& M.P. Lima (Leguminosae - Mimosoideae) de populações ocorrentes em dois remanescentes de Floresta Atlântica. Acta Botânica Brasilica, v.20, p.839-44, 2006.

RÍOS, J.L.; RECIO, M.C. Medicinal plants and antimicrobial activity. Journal of Ethnopharmacology, v.100, p.80-4, 2005. SANTOS, E.; MARANGON, L.C.; RAMALHO, R.S. Levantamento dendrológico da Bacia do Rio São Bartolomeu, Viçosa - MG. Revista Ceres, v.45, p.339-49, 1998.

STOREY, C.; SALEM, J.I. Lay use of Amazonian plants for the treatment of tuberculosis. Acta Amazonica, v.27, p.17582, 1997.

VAN VLIET, G.L.C.M.; BAAS, P. Wood anatomy and classification of the Myrtales. Annals of the Missouri Botanical Garden, v.71, p.783-800, 1984.

WHEELER, E.A. et al. Computer-aided wood identification: reference manual. Madison: North Carolina Agricultural Research Service, Department of Wood and Paper Science, 1986. 160p.

WILKINS, A.P.; PAPASSOTIRIOU, S. Wood anatomical variation of Acacia melanoxylon in relation to latitude. IAWA Bulletin, v.10, p.201-7, 1989.

WILSON, E.O.; PETER, F.M. Biodiversity. Washington: National Academic Press, 1995. 521p. 